\title{
Relationship between corneal arcus and hyperlipidaemia is clarified by studies in familial hypercholesterolaemia
}

\author{
A. F. WINDER \\ From the Institute of Ophthalmology and the Lipid Clinic, St Bartholomew's Hospital, London EC1
}

SUMMARY In subjects with familial hypercholesterolaemia for whom integrated exposure to hyperlipoproteinaemia can be determined, arcus development correlates with age rather than extent or pattern of hyperlipoproteinaemia. This permissive effect whereby arcus development becomes progressively time-dependent rather than dose-dependent at increasing levels of hyperlipoproteinaemia may underlie difficulties in the interpretation of premature corneal arcus in less specific disorders. Arcus development is not apparently influenced by levels of high-density lipoprotein in plasma.

Patients with premature corneal arcus may be hyperlipidaemic. However, it is the common experience that patients selected because of either hyperlipidaemia or accelerated corneal arcus do not show any obvious association between the extent of these 2 disorders. A probable reason for this discrepancy is that most patients with hyperlipidaemias do not have primary disorders, nonfamilial type IIa and IIb disorders being the most common finding. ${ }^{1-3}$ These secondary hyperlipidaemias may fluctuate in extent and are very unlikely to have been present from early life. Thus the extent and duration of the hyperlipidaemia prior to assessment cannot be estimated, only the extent at the time of analysis. Furthermore, there is no clear evidence in man that regression of corneal arcus is achieved by control of any associated hyperlipidaemia, further obscuring any general relationship with a fluctuating or intermittent hyperlipidaemia.

In attempting to define any such general relationship, forms of familial hypercholesterolaemia (FH) are of special interest. Accelerated development of corneal arcus is common and in these disorders the plasma lipoprotein patterns are broadly consistent from early life until diagnosis and treatment, irrespective of age. ${ }^{45}$ Thus integrated exposure to hyperlipidaemia and to levels of specific lipoprotein components in plasma can be calculated, and possible

Correspondence to Dr A F Winder, Department of Chemical Pathology, Leicester Royal Infirmary, Leicester LE1 5WW. associations with the development of corneal arcus can then be assessed.

Clinical and biochemical observations were recorded for patients homozygous and heterozygous for FH. The extent of corneal arcus was assessed on a graded scale, and the relationship with extent and pattern of dyslipoproteinaemia was assessed mainly from data recorded for new heterozygotes seen at presentation before treatment.

\section{Patients and methods}

SELECTION OF PATIENTS

Nineteen male and 8 female heterozygotes were identified and assessed on presentation over a 4-year period at the Lipid Clinic of St Bartholomew's Hospital. Diagnosis was made from symptoms and signs at presentation, lipoprotein profiles, and family studies, with some exclusion of other causes of hyperlipoproteinaemia. Studies of cell-surface receptors for low-density lipoprotein (LDL) were not regularly performed. Observations recorded are shown in Tables 1 and 2. Corneal arcus or xanthelasmata had led to presentation of some cases, but many asymptomatic cases were diagnosed through family studies and no selection bias other than survival was apparent.

The six homozygotes seen were attending the Hammersmith Hospital, London, for plasma 789 exchange. Diagnosis had been previously established, 
Table 1 Heterozygous familial hypercholesterolaemia: male patients assessed at presentation, before treatment

\begin{tabular}{|c|c|c|c|c|c|}
\hline No. & Age seen & Presentation & Arcus grade & Xanthelasma & Xanthoma \\
\hline 1 & 42.0 & Large xanthelasma for 18 months & 1 & + & 0 \\
\hline 2 & 31.2 & Screen in affected family: asymptomatic & 2 & 0 & ++ \\
\hline 3 & 22.9 & Arcus noted age 22.6 by general practitioner & 3 & 0 & 0 \\
\hline 4 & 40.4 & Incidental: invetigation of headaches & 1 & + & + \\
\hline 5 & 53.5 & Investigation of tinnitus and deafness & 1 & 0 & + \\
\hline 6 & 27.6 & Arcus seen on removal of corneal foreign body & 2 & 0 & ++ \\
\hline 7 & 48.2 & Xanthelasmata for 3 years & 1 & + & 0 \\
\hline 8 & 23.10 & Screen in affected family: asymptomatic & 0 & 0 & + \\
\hline 9 & 31.1 & Investigation of chest pain age 30.9: heart normal & 1 & 0 & $\begin{array}{l}0 \\
+ \text { age } 34.3\end{array}$ \\
\hline 10 & 17.9 & Screen in affected family: asymptomatic & 0 & 0 & 0 \\
\hline 11 & 37.0 & Investigation of chest pain age 36 : hiatus hernia found & 2 & 0 & 0 \\
\hline 12 & 23.2 & Screen in affected family: asymptomatic & 0 & 0 & ++ \\
\hline 13 & 50.6 & Large xanthelasmata age 50 & 3 & + & ++ \\
\hline 14 & 45.1 & Lipaemia at executive screen: asymptomatic & 1 & 0 & + \\
\hline 15 & 39.0 & Small xanthelasma age 33: asymptomatic & 1 & + & + \\
\hline 16 & 69.0 & Screen in affected family: asymptomatic & 4 & 0 & ++ \\
\hline 17 & 11.4 & Screen in affected family: asymptomatic & 1 & 0 & 0 \\
\hline 18 & 48.1 & Xanthelasmata for 18 months & $3+$ & + & + \\
\hline 19 & 51.10 & $\begin{array}{l}\text { Routine investigation at surgery for acute jejunal stricture } \\
\text { age 50.9. MI age } 40\end{array}$ & 2 & 0 & + \\
\hline
\end{tabular}

LBBB $=$ left bundle branch block. $\mathrm{C}=$ cholesterol. $\mathrm{MI}=$ myocardial infarct. $\mathrm{TG}=$ triglycerides. Xanthoma: ++ indicates lesions at 2 independe sites-e.g., hands and heels.

and various other studies of some of these rare patients have been published. $\rightarrow-9$ Heterozygotes numbers 26 and 27 are twins, presumed nonidentical; 10,12 , and 20 are siblings, and 16 is the father of 15 . The homozygotes are unrelated to the heterozygotes or to each other, and observations are shown in Table 3.

\section{CLINICAL ASSESSMENT}

Full general and ophthalmological examination was performed by the author. The degree of arcus was evaluated. using a hand-held ophthalmoscope on a scale of $0-4$ similar to previous methods ${ }^{10}{ }^{11}$ : grade 1 , upper or lower segment arcus; grade 2, both segments affected; grade 3, both segments and just confluent; grade 4, heavy confluent arcus.

Various cardiovascular assessments were also performed. All heterozygotes had fasting levels of glucose in plasma within the normal range and were not hypertensive.

BIOCHEMICAL ASSESSMENT

Fasting lipoprotein profiles were obtained for new heterozygotes on at least 2 occasions, average values being cited. Levels of total high-density lipoprotein (HDL) cholesterol in plasma were also obtained for some patients by the manganese chloride/heparin

Table 2 Heterozygous familial hypercholesterolaemia: female patients assessed at presentation, before treatment

\begin{tabular}{|c|c|c|c|c|c|}
\hline No. & Age seen & Presentation & Arcus grade & Xanthelasma & Xanthoma \\
\hline 20 & 25.3 & Screen in affected family: asymptomatic & 1 & 0 & + \\
\hline 21 & 54.2 & $\begin{array}{l}\text { Investigated as strong family history of premature heart } \\
\text { disease: asymptomatic }\end{array}$ & $2+$ & 0 & + \\
\hline 22 & 34.2 & Arcus noted by optician & 3 & 0 & + \\
\hline 23 & 19.10 & Screen in affected family: asymptomatic & 0 & 0 & 0 \\
\hline 24 & 58.2 & Bilateral xanthelasmata noticed age 58 & 2 & + & + \\
\hline 25 & 57.6 & Investigation of progressive tinnitus and deafness & 4 & 0 & + \\
\hline 26 & 51.2 & Screen in affected family: asymptomatic twins & 3 & 0 & + \\
\hline 27 & 51.2 & Screen in affected family: & 3 & 0 & + \\
\hline
\end{tabular}

Cases 26 and 27 are bracketed because they are twins. 


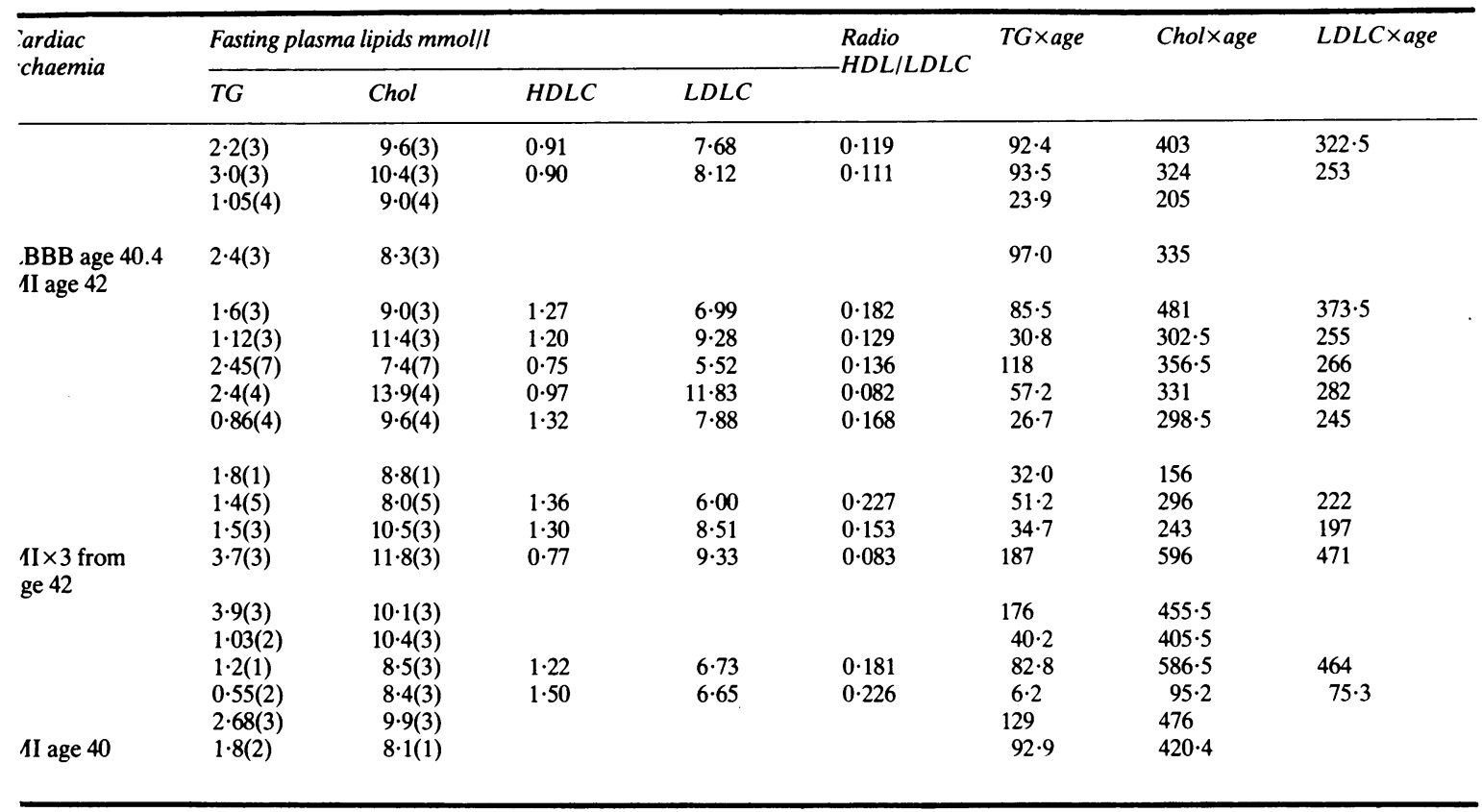

procedure. Levels of LDL cholesterol were then calculated. ${ }^{12}$ Data were available for homozygotes before and during treatment. Partial reduction in levels of cholesterol in plasma had been achieved with homozygous patients $\mathrm{B}, \mathrm{D}$, and $\mathrm{F}$ by plasma exchange for periods of approximately 1,2 , and 3 years, plus a brief further reduction in patient B achieved by a portocaval shunt. These minor responses were well documented and it was possible therefore to calculate corrected integrated exposure (see below) as shown in Table 3. Lipoprotein values cited were not recorded within 3 months of an episode of acute myocardial ischaemia to avoid artefactual results.
EVALUATION OF DATA

Clinical and biochemical data recorded for the 19 male and 8 female heterozygotes assessed at presentation were subjected to multivariate analysis by the SPSS programme, determining intervariable correlation coefficients and their levels of significance for each group and for both groups combined. The derived terms additionally incorporating age represent integrated exposure at assessment. Thus a patient presenting at age 27.5 years with an average level of total cholesterol in plasma of $10 \mathrm{mM}$ has an integrated exposure for total cholesterol of 275 units.

\begin{tabular}{|c|c|c|c|c|c|c|c|c|}
\hline \multirow{2}{*}{$\begin{array}{l}\text { Zardiac } \\
\text { schaemia }\end{array}$} & \multicolumn{4}{|c|}{ Fasting plasma lipids mmol/l } & \multirow{2}{*}{$\begin{array}{l}\text { Ratio } \\
H D L / L D L C\end{array}$} & \multirow[t]{2}{*}{ TG $\times$ age } & \multirow[t]{2}{*}{ Chol $\times$ age } & \multirow[t]{2}{*}{$L D L C \times a g e$} \\
\hline & $T G$ & $\operatorname{Chol}(C)$ & $H D L C$ & $L D L C$ & & & & \\
\hline ) & $1 \cdot 3(3)$ & $9 \cdot 5(3)$ & $1 \cdot 17$ & $7 \cdot 73$ & $0 \cdot 151$ & $32 \cdot 8$ & 240 & 195 \\
\hline ) & $1 \cdot 5(3)$ & $8 \cdot 0(3)$ & & & & $81 \cdot 2$ & $433 \cdot 5$ & \\
\hline ) & $1 \cdot 35(2)$ & $9 \cdot 7(2)$ & $2 \cdot 1$ & $6 \cdot 98$ & $0 \cdot 301$ & $46 \cdot 1$ & $331 \cdot 5$ & $238 \cdot 5$ \\
\hline 1 & $1 \cdot 35(3)$ & $8 \cdot 1(3)$ & $1 \cdot 26$ & $6 \cdot 22$ & $0 \cdot 203$ & $26 \cdot 8$ & $160 \cdot 5$ & $123 \cdot 5$ \\
\hline 1 & $2 \cdot 4(3)$ & $10 \cdot 3(3)$ & & & & $139 \cdot 5$ & 599 & \\
\hline ) & $1 \cdot 13(3)$ & $11 \cdot 2(3)$ & $2 \cdot 54 / 12 \cdot 4$ & $9 \cdot 22$ & 0.275 & $65 \cdot 0$ & 644 & 530 \\
\hline ) & $1 \cdot 25(3)$ & $8 \cdot 35(4)$ & $1 \cdot 3$ & $6 \cdot 48$ & $0 \cdot 200$ & 64 & 427 & $331 \cdot 5$ \\
\hline ) & $1 \cdot 45(3)$ & $9 \cdot 3(3)$ & $1 \cdot 25$ & $7 \cdot 38$ & $0 \cdot 169$ & $74 \cdot 2$ & 476 & 378 \\
\hline
\end{tabular}


Table 3 Homozygous familial hypercholesterolaemia. Data on 6 patients showing arcus grade at age of assessment and fasting plasma lipids with integrated exposure to hypercholesterolaemia, after correction for short-term responses to treatment with patients $B, D$, and $F$

\begin{tabular}{|c|c|c|c|c|c|c|c|c|}
\hline Patien & Age/sex & Arcus grade & Xanthelasma & Xanthoma & Cardiac status & Chol mmolll & $T G \mathrm{mmol} / \mathrm{l}$ & Chol $\times$ age \\
\hline A & $5 \cdot 3 \mathrm{~F}$ & 1 & 0 & ++ & $\begin{array}{l}\text { Aortic stenosis, silent } \\
\text { coronary occlusion }\end{array}$ & $23 \cdot 6$ & $1 \cdot 19$ & 126 \\
\hline B & $28.9 \mathrm{~F}$ & 0 & 0 & + & $\begin{array}{l}\text { Aortic stenosis, } \\
\text { CAVBG } \times 3\end{array}$ & $16 \cdot 1-11 \cdot 4$ & $2 \cdot 0$ & $461 \cdot 5$ \\
\hline C & $15 \cdot 3 \mathrm{M}$ & 2 & 0 & ++ & Aortic stenosis & $19 \cdot 8$ & $1 \cdot 8$ & 287 \\
\hline D & $16 \cdot 5 \mathrm{M}$ & 2 & 0 & ++ & $\begin{array}{l}\text { Aortic stenosis, } \\
\text { ostial narrowing }\end{array}$ & $20 \cdot 1-8 \cdot 4$ & 1.07 & 280 \\
\hline E & $19 \cdot 5 \mathrm{M}$ & $1 / 2$ & + & ++ & $\begin{array}{l}\text { Aortic stenosis } \\
\text { CAVBG }\end{array}$ & $18 \cdot 0$ & $1 \cdot 85$ & 344 \\
\hline F & $26 \cdot 7 \mathrm{M}$ & 3 & 0 & ++ & Silent MI age 22 & $15 \cdot 5-8 \cdot 7$ & 0.9 & 385 \\
\hline
\end{tabular}

Levels of HDL in plasma were depressed in all patients. Patient $E$ showed unequal development of arcus.

$\mathrm{CAVBG}=$ coronary artery vein bypass graft.

Variables and the total number of values recorded were:

$\begin{array}{ll}\text { age of patient } & (27) \\ \text { arcus grade } & (27) \\ \text { cholesterol } & (27) \\ \text { triglycerides } & (27) \\ \text { HDL cholesterol } & (18) \\ \text { LDL cholesterol } & (17) \\ \text { HDL/LDL chol. ratio } & (18) \\ \text { triglycerides } \times \text { age } & (27) \\ \text { cholesterol } \times \text { age } & (27) \\ \text { HDL chol. } \times \text { age } & (18) \\ \text { LDL chol. } \times \text { age } & (17) \\ \text { HDL/LDL chol. ratio } \times \text { age } & (18)\end{array}$

A mean value for LDL cholesterol is not given for patient 25 in view of sample variation, but values for HDL cholesterol and HDL/LDL cholesterol ratio for a specific sample are cited.

\section{Results}

In the multivariate analysis it was assumed that arcus grade could be used as both a discrete and continuous variable, and analysis of the combined data for new heterozygotes supported a linear trend of arcus grade with age by means of a one-way analysis of variance with contrasts. Mean age of patients and numbers for each arcus grade were as follows:

$\begin{array}{ll}\text { Grade 0 } & 21.1 \text { years }(4) \\ \text { Grade 1 } & 37.3 \text { years }(9) \\ \text { Grade 2 } & 43.2 \text { years }(6) \\ \text { Grade 3 } & 43.0 \text { years }(6) \\ \text { Grade 4 } & 63.3 \text { years (2) }\end{array}$

Analysis indicated a clear positive correlation between arcus grade and age for the 19 male heterozygotes $(r=0.535, s=0.009)$. the 8 females $(r=0.724$, $\mathrm{p}=0.021)$ and for all 27 heterozygotes combined $(\mathrm{r}=$ $0 \cdot 616, s=0 \cdot 001$ ).

This correlation may be expressed as a linear relationship, shown with calculated regression lines for the combined group and for males only in Fig. 1.
CORNEAL ARCUS AND PATTERNS OF

DYSLIPOPROTEINAEMIA

Significant correlations were not obtained between arcus grade and plasma triglycerides or total cholesterol, LDL cholesterol, or with the HDL/LDL cholesterol ratio (limited data were available). Correlations were obtained with these values and with HDL cholesterol as integrated terms additionally

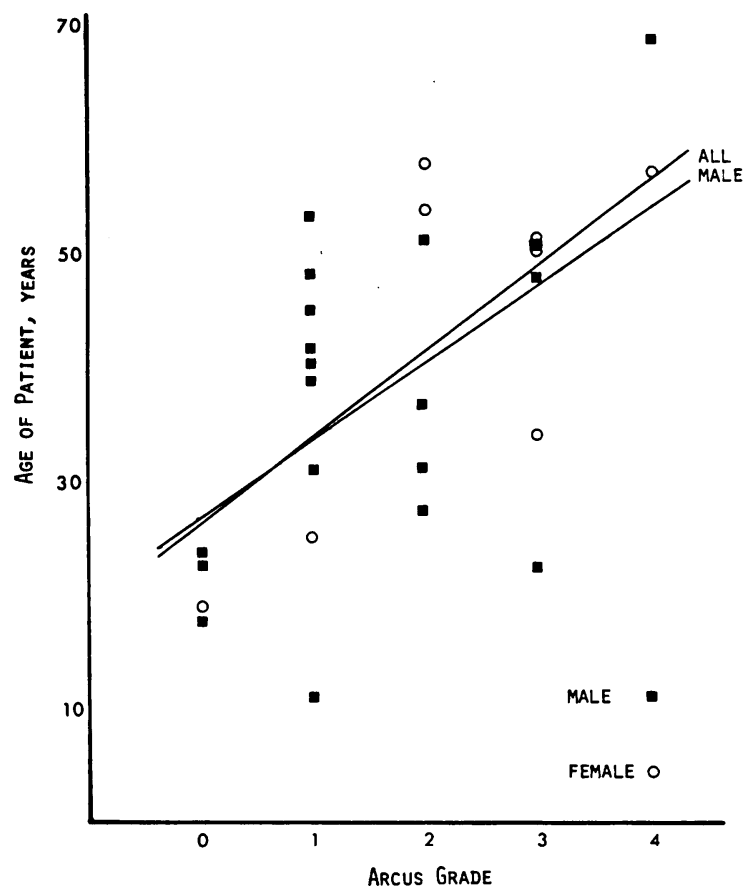

Fig. 1 Corneal arcus and familial hypercholesterolaemia. Relationship between age and arcus grade for heterzygotes at presentation. Regression lines were derived for: All patients: age $=26 \cdot 19+7 \cdot 59$ arcus grade. Males only: age $=26 \cdot 96+6 \cdot 91$ arcus grade. 
incorporating age, but these were invalid in view of the correlation with age alone. However, the relationship between arcus grade and (plasma cholesterol $\times$ age) is of interest, as data for the 6 homozygotes may be included after correction for minor responses to treatment as shown in Table 3. This relationship is shown in Fig. 2, with the regression lines for heterozygotes to which the additional data also broadly conform.

A moderate positive correlation between arcus grade and HDL cholesterol with the combined group of heterozygotes $(r=0.420, p=0.041)$ was not found with the male and female patients alone, the non-significant correlation for males being negative.

\section{Discussion}

A general relationship between age of patient and extent of corneal arcus is widely recognised, but factors influencing the development of corneal arcus are clarified in the extreme case of familial hypercholesterolaemia. Development is related to the patients' age and thus to the duration of hyperlipo-

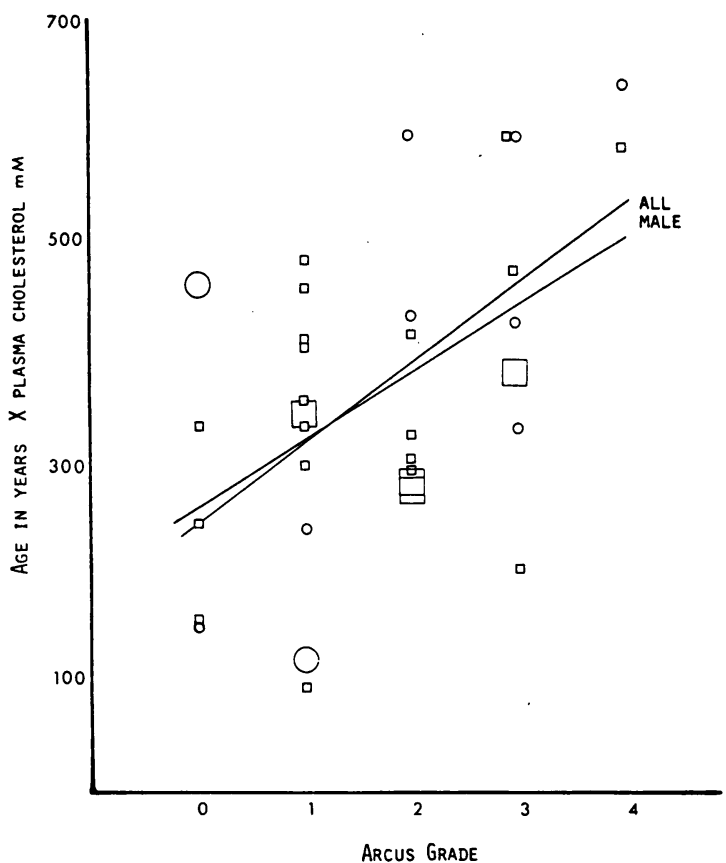

Fig. 2 Corneal arcus and familial hypercholesterolaemia. Arcus grade and age $\times$ plasma cholesterol for heterozygotes at presentation and for homozygotes-large points-on treatment. Males, square points; females, circles. Regression times for heterozygotes were derived for: All patients: age $\times$ chol.$=245.02+73.55$ arcus grade. Males only: age $\times$ chol. $=264.33+59.98$ arcus grade. proteinaemia, rather than to its extent or pattern, over a wide range of exposure.

The overriding relationship with age is consistent with a permissive effect and a saturation process, becoming progressively time-dependent rather than dose-dependent with increasing hyperlipidaemia and particularly with excess of low-density lipoprotein. This indirect relationship probably contributes to the more general problem of assessment of the clinical significance of corneal arcus in patients with a background of hyperlipidaemia, which is less specific or consistent than with monogenic familial hypercholesterolaemia. An added complication is that arcus is a cumulative process which is not known to regress in man, and appears to be unaffected by reduction in level of any associated hyperlipidaemia. Further racial and local factors above this permissive effect may contribute to the observed wide individual variation, including differential carotid stenosis, as with homozygous patient $\mathrm{E}$, local corneal temperature and limbal blood flow, and secondary changes in long-standing insudated deposit, which impair remobilisation. ${ }^{913}$

The level of HDL in plasma is a negative risk factor for ischaemic heart disease. Limited data in the present study suggest that levels of HDL in plasma or the HDL/LDL cholesterol ratio do not significantly influence arcus development. The same data have also shown that the development of xanthelasmata, in which lipid deposits are intracellular in contrast to those of corneal arcus, are promoted by hypertriglyceridaemia and relative deficiency of HDL, although the 2 factors are not independent. These observations further reinforce the dissociation between cardiovascular disease and arcus development.

The co-operation of Dr D. J. Galton and Dr G. R. Thompson with clinical studies, $\mathrm{Mr} \mathrm{H}$. Donovan with statistical procedures, and Mrs B Payne and Dr J. Stocks with biochemical analyses is gratefully acknowledged.

\section{References}

1 Parwaresch MR, Haacke H, Mäder $\mathrm{Ch}$, Godt $\mathrm{Ch}$. Arcus lipoides Cornea und hyperlipoproteinaemia. Klin Wochenschr 1976; 54: 495-7.

2 Rosenman RH, Brand RJ, Scholtz MS, Jenkins CD. Relation of corneal arcus to cardiovascular risk factors and the incidence of coronary disease. $N$ Eng J Med 1974; 291: 1322-4.

3 Cooke NT. Significance of arcus senilis in Caucasians. $J$ R Soc Med 1981; 74: 201-4.

4 Kwiterovich PO, Fredrickson DS, Levy RI. Familial hypercholesterolemia (one form of familial type II hyperlipoproteinemia). A study of its biochemical, genetic and clinical presentation in childhood. J Clin Invest 1974; 53: 1237-9.

5 Slack J, Preece M, Giles P. Identification of children who are heterozygotes or familial hypercholesterolemia. In: Gotto AM, Smith LC, Allen B, eds. Athersclerosis $V$. New York: Springer, 1980: 244-9. 
6 Soutar AK, Myant NB, Thompson GR. Simultaneous measurement of apolipoprotein B turnover in very low- and low-density lipoproteins in familial hypercholesterolemia. Atherosclerosis 1977; 28: 247-56.

7 Thompson GR, Myant NB, Kilpatrick D, Oakley CM, Raphael MJ, Steiner RE. Assessment of long-term plasma exchange for familial hypercholesterolaemia. Br Heart J 1980; 43: 680-8.

8 Thompson GR, Lowenthal R, Myant NB. Plasma exchange in the management of homozygous familial hypercholesterolaemia. Lancet 1975 ; i: $1208-11$.

9 Winder AF. Factors influencing the variable expression of xanthelasmata and corneal arcus in familial hypercholesterolemia.
In: Cotlier E, Maumenee IH, Berman ER, eds. Genetic eye diseases. Birth Defects 1982; 18: 449-62.

10 Tschetter RT. Arcus senilis. Its relationship to serum lipids in the negro male. Arch Ophthalmol 1980; 76: 325-8.

11 Macaraeg PVJ, Lasagna L, Snyder B. Arcus not so senilis. Ann Intern Med 1968; 68: 345-54.

12 Friedenwald WT, Levy RI, Fredrickson DS. Estimation of the concentration of low-density lipoprotein cholesterol in plasma, without use of the preparative ultracentrifuge. Clin Chem 1972; 18: 499-502.

13 Sheraidah GAK, Winder AF, Fielder AR. Lipid protein constituents of human corneal arcus. Atherosclerosis 1981; 40: 91-8. 